\title{
UMA ABORDAGEM SOCIOCOGNITIVA DA NARRATIVA FANTÁSTICA
}

Fábio Lucas Pierini (UEM)

Recebido em 04 ago 2017. Fábio Lucas Pierini é Doutor em Estudos linguísticos, Aprovado em 25 ago 2017. literários e tradutológicos pela FFLCH-USP com pósdoutorado em Estudos Literários pela Unesp FCL/CAr. Professor na UEM (Maringá-PR), atuando nos cursos de Secretariado Executivo Trilíngue e Letras na área de Língua e Literatura Francesas, leciona e orienta a respeito de narrativa fantástica no Programa de PósGraduação em Letras e no Programa de Iniciação Científica. Participa do GT Anpoll Vertentes do Insólito Ficcional e do Grupo CNPq Estudos de literatura e cultura da Belle Époque: LABELLE.

Resumo: O estudo da narrativa fantástica passa, desde seus primórdios, por várias dificuldades metodológicas que podem ser resumidas à estratégia dos pesquisadores de evitar confrontos com sistemas de crenças do mundo real. No entanto, se situarmos o fantástico em seu contexto de consolidação, o Romantismo europeu do século XIX, perceberemos que sua função social é a de defender um sistema de crenças que sustentava um modo de vida originário do neolítico frente a sua destruição por parte da revolução industrial. Essas narrativas, porém, só se tornam inteligíveis na medida em que encontram respaldo na mente humana, a qual evoluiu desde o pleistoceno para detectar padrões no meio ambiente 
e daí extrair relações de causa e efeito que permitam sua sobrevivência. Uma das conclusões à qual a mente humana chega quando da verificação desses padrões é a agência, ou seja, que alguma entidade invisível agiu intencionalmente visando um determinado objetivo. Por outro lado os seres humanos enxergam a realidade por meio de narrativas sempre dentro da estrutura universal: Personagem + Problema $\rightarrow$ Perspectiva de solução do problema; o que lhes permite personalizar eventos de causa desconhecida e torná-los compreensíveis. No entanto, como a noção do real é modificada na medida em que a ciência e a tecnologia progridem, nossa competência de verossimilhança se torna mais exigente e a saída encontrada pelos autores da época foi tratar de temas e motivos populares da Idade Média a partir de um discurso científico e ou estilo jornalístico, conferindo plausibilidade aos eventos narrados. Por essa razão, o estudo da narrativa fantástica depende de uma abordagem que leve em conta tanto os aspectos socioculturais da coletividade em que se manifesta quanto nossa capacidade de enxergar a realidade por meio de estruturas narrativas e dar sentido aos padrões detectados no meio ambiente. Trata-se, portanto, de uma abordagem sociocognitiva.

Palavras-chave: Narrativa fantástica; Abordagem sociocognitiva; Psicologia evolutiva; Antropologia cognitiva.

Résumé: L'étude du récit fantastique subit dès ses débuts par nombre de difficultés méthodologiques qu'on peut réduire à la stratégie des chercheurs d'éviter le conflit avec des systèmes de croyance du monde réel. Toutefois, si l'on situe le fantastique dans son contexte de consolidation, le Romantisme Européen du XIXème siècle, on s'aperçoit que sa fonction sociale était justement celle de défendre un système de croyances qui soutenait un mode de vie originaire du Néolithique en train d'être détruit par la Révolution 
industrielle. Ces récits, néanmoins, ne deviennent intelligibles que quand ils trouvent de l'écho dans l'esprit humain, lequel a évolué dès le Pléistocène pour détecter des formes dans l'environnement et en extraire des rapports de cause et d'effet pour survivre. Une des conclusions que l'esprit humain en tire lorsqu'il vérifie ces formes c'est l'agence, cela veut dire qu'une entité invisible quelconque a agi intentionnellement envisageant un but déterminé. D'un autre côté, les êtres humains comprennent la réalité par le moyen de récits toujours dans le schéma universel Personnage, Problème, Perspective de solution du problème, ce qui leur permet de personnaliser des événements de cause inconnue et les rendre compréhensibles. Toutefois, comme la notion du réel est modifiée chaque fois que la Science et la Technologie progressent, nôtre compétence du vraisemblable devienne-t-elle encore plus exigeante et la sortie trouvée par les auteurs de l'époque a été de traiter des thèmes et motifs populaires du Moyen Âge à partir d'un discours scientifique et ou d'un style journalistique pour conférer de la plausibilité aux événements racontés. Pour cette raison, l'étude du récit fantastique dépend d'une approche envisageant aussi les aspects socioculturels de la collectivité dans laquelle il se manifeste que notre capacité de comprendre la réalité par le moyen de schémas narratifs et donner du sens aux formes détectées dans l'environnement. II s'agit donc d'une approche sociocognitive.

Mots-clés: Récit fantastique; Approche sociocognitive; Psychologie évolutive; Anthropologie cognitive.

\section{INTRODUÇÃO}

A nosso ver, um dos maiores problemas no estudo da narrativa fantástica é a máxima segundo a qual não podemos "sair" do texto para poder interpretá-lo ou entendê-lo. Entretanto, uma narrativa 
de ficção não é - ou ao menos não se consolidou na cultura humana para ser - um exercício intelectual para apreciação estética do leitor, ou seja, algo desvinculado das crenças e objetivos, tanto de quem a produz quanto de quem a consome. Para se realizar enquanto interação cultural, a leitura deve proporcionar uma experiência significativa para leitor e autor na medida em que ambos consigam desfrutar de um estado de identificação mútua e construir para si um espaço que justifique sua presença no mundo, isto é, sua existência.

Nada justifica melhor uma existência do que a autorrealização, a qual consiste em ser reconhecido por produzir algo considerado útil pela coletividade na qual estamos inseridos. Escrever uma história que vai ser lida por milhões, talvez bilhões de leitores, é certamente uma proeza dessas. Ler uma história que ajude a encontrar um propósito para nossa existência nos auxilia a suportar as agruras da vida porque reforça nossas crenças e reanima a busca por nossos objetivos.

Mas o que é que autor e leitor buscam compartilhar por meio da narrativa fantástica? Ainda que os estudiosos da literatura resistam em considerar, é preciso admitir que quando produzimos e consumimos narrativas fantásticas estamos compartilhando uma visão de mundo que dá sentido às nossas vidas, ou seja, estamos defendendo um sistema de crenças.

Muitos afirmam que a narrativa fantástica promove uma suspensão temporária na descrença do leitor (TODOROV, 1969). Outros que a leitura permite um estado de sideração (GRIVEL, 1997; MELLIER, 1999) que nos recorta da realidade imediata, sequestrando-nos para o universo em que a história é contada. Defende-se até que seja uma necessidade natural de entender e enfrentar nossos temores por meio da simulação da emoção 
do medo (MOLINO, 1980; LOVECRAFT, 2008; PRINCE, 2008). Ou, como já mencionado anteriormente, que se trata de um exercício intelectual visando à fruição intelectual do leitor (BESSIÈRE, 1974). Tudo isso é dito somente por causa da coerência teórica de não "sair" do texto, isto é, para considerarmos apenas a letra fria, a cadeia de frases, a sequência de parágrafos e mais nada. Além disso, essas afirmações teórico-críticas são enunciadas de maneira a driblar o conceito de verossimilhança, o grande entrave das análises e interpretações das narrativas fantásticas.

Por que não atacá-lo de frente? Por que não tentar entender a razão que permite ao leitor considerar inteligíveis as narrativas fantásticas? Afinal, se o leitor entende uma história é porque ela faz sentido para ele e, portanto, é-lhe verossímil. Como pode ser verossímil uma narrativa sobre um fenômeno sobrenatural reconhecido como impossível no mundo real? A saída encontrada, mais política do que teórica, conforme ensinam nossos professores de literatura, é que os fenômenos sobrenaturais "possíveis" do mundo real pertencem a outro domínio que não o do fantástico e, caso uma narrativa trate deles, não estaríamos mais no domínio da ficção.

Percebam que aqui mais uma vez estamos caindo no problema da excessiva coerência teórica. Além da desculpa de que a narrativa de ficção não foi feita para se acreditar, e para isso amontoam-se remendos explicativos. Alega-se também que o fantástico, assim como outros gêneros, tipos e modos textuais, tende a uma pureza de formas e características que o distinguem dos demais. Aliás, o termo "modo" (CESERANI, 2006) foi adotado para lidar com o fantástico justamente porque não se conseguia classificá-lo como gênero segundo os critérios da teoria literária. 
Outro problema no estudo da narrativa fantástica é tentar estudá-la à parte, como se fosse uma forma de narrar independente das demais, ignorando que ela esteja sujeita aos mesmos princípios destas e que os leitores em geral mobilizam os mesmos mecanismos cognitivos para ler qualquer história. Mais do que isso, costumamos ignorar o que pensa o próprio leitor sobre o que ele considera ser uma narrativa fantástica, como médicos que examinam um paciente ignorante de sua enfermidade. Existe também o problema de tentar enquadrar o fenômeno literário na definição etimológica da palavra que o designa, e muitos acabam por atribuir à narrativa fantástica os mesmos predicados que o dicionário consagra ao adjetivo "fantástico".

Qualquer leitor sabe o que é uma narrativa fantástica. Trata-se simplesmente de uma narrativa de ficção situada em nosso mundo na qual ocorrem fenômenos inverificáveis ou irreproduzíveis do ponto de vista das ciências naturais. Quase todo crítico, teórico ou professor de literatura parte dessa afirmação. Porém, depara-se com várias narrativas que mais ou menos fogem dela por haver em seu enredo elementos sobrenaturais pertencentes a uma cultura que os considera reais. $O$ gosto ou interesse de alinhar determinadas narrativas ou autores a uma coletânea definitiva ou modelar do fantástico também ajudou a criar vários remendos explicativos a uma definição praticamente universal.

Mais do que o gosto e a vaidade, também é preciso considerar aspectos políticos e ideológicos. Em busca de valorizar determinadas identidades e coletividades, épocas e lugares, várias nomenclaturas foram adotadas como, por exemplo, realismo mágico, real maravilhoso, realismo fantástico, realismo animista, insólito, entre 
outros. Evidentemente que nada há de errado com esses rótulos, afinal o objetivo deles é limitar nosso campo de atuação para economizarmos tempo e recursos na realização de uma pesquisa. O que nos prejudica é a criação e aplicação de novos rótulos por causa de diferenças que muitas vezes extrapolam a interação cultural entre autor e leitor e que em nada agregam para ajudar a entender a narrativa propriamente dita, ou seja, de que forma ela se consolida como uma experiência significativa para ambos.

Outro problema causado pela rotulação desenfreada é a tentativa de fazer caber num conceito dicionarizado, consolidado numa determinada cultura, o significado de uma manifestação literária muitas vezes indiferente a esse conceito. Os casos do fantástico, do realismo mágico e do insólito, que se encontram de alguma forma documentados, mostram a dificuldade que se torna estudar uma produção narrativa dentro de definições dicionarizadas e não a partir delas.

A nosso ver, o segredo do funcionamento da narrativa fantástica é o mesmo de qualquer outra narrativa: a interação entre nossa capacidade de buscar a verossimilhança em qualquer história que nos contem e o grau de realismo com que os elementos sobrenaturais são tratados. Em nenhum momento suspendemos nossas crenças para ler uma narrativa de ficção e, mesmo que o quiséssemos fazer, nossa mente automaticamente faria isso por nós porque sem elas nenhuma narrativa fantástica se torna inteligível a ponto de ser significativa.

\section{E O QUE ESTAMOS CHAMANDO DE CRENÇAS ENTÃO?}

Crença é tudo aquilo que consideramos verdadeiro ou ao menos passível de ser verdadeiro, mesmo que não possamos 
provar, mas que pode ser tornado demonstrável ou defensável por meio de uma narrativa. Tudo aquilo que não podemos testemunhar nem vivenciar só nos é dado a conhecer por meio da linguagem. E essa linguagem precisa ser organizada em cadeias de causa e efeito que se coadunem com nossa competência de verossimilhança ou não podemos "simular" a vivência ou testemunho apresentados (BOYD, 2009). É como se toda história fosse uma receita de bolo: se não tivermos previamente os ingredientes em nossa memória, é impossível simular a contento os fatos narrados. É isso o que muitos professores de literatura chamam de "bagagem" quando justificam que só depois de muito tempo estudando e conhecendo o mundo é que podemos reler certos textos e passar a entendê-los.

No entanto, as narrativas que dependem de ingredientes específicos para ser compreendidas são, de fato, exercícios intelectuais que esperam uma fruição estética por parte do leitor. Mas esse leitor não é o leitor em geral e sim aquele que tem na leitura um prazer além do normal e não aquele que, em muitos casos, o professor de literatura vai encontrar nas salas de aula do ensino fundamental e médio - e muitas vezes nem no ensino superior.

A narrativa fantástica, assim como nossas crenças, não depende necessariamente de ingredientes extras e por isso ela faz tanto sucesso e é tão difícil de ser estudada e assimilada pelos Estudos Literários: como justificar o tempo e recursos gastos para pesquisar um assunto que qualquer leitor pode entender sem maiores investimentos intelectuais? Ora, a resposta está justamente nas dificuldades apontadas até agora no estudo da narrativa fantástica: 
a profusão terminológica e a rigidez dos critérios de leitura (interpretação e análise).

Nós já nascemos com os ingredientes que tornam possível a compreensão da narrativa fantástica em nossa mente e eles são os mesmos que sustentam as nossas crenças. Assim como textos religiosos ou explicações pseudocientíficas atendem às exigências da nossa competência de verossimilhança para entender os processos invisíveis por trás de uma relação de causa e efeito, o fantástico se torna uma narrativa inteligível e proporciona uma experiência significativa porque se apresenta como plausível dentro do quadro realista em que é contada.

Para entender a narrativa fantástica em sua complexidade, precisamos focalizar nossa atenção a pelo menos quatro fatores que a compõem:

- O contexto da sua consolidação no Romantismo europeu do século XIX;

- O progresso da tecnologia e seu impacto na visão de mundo do leitor;

- O conflito entre percepção e consciência diante do desconhecido;

- O papel da arte como mediadora desses conflitos;

O contexto do Romantismo (século XIX) não é necessariamente aquele que cria o fantástico, mas o que proporciona as condições de sua consolidação enquanto forma de narrar dotada de características distintivas, pois fornece as motivações e técnicas narrativas de que autores e leitores se alimentam para criar uma identificação mútua de seu anseio por um propósito para a vida 
humana, em conflito com as transformações radicais impostas à sociedade ocidental pelo acirramento das ações do capitalismo que tornam a ideia de transcendência - essencial em sociedades préindustriais - obsoleta.

O progresso da tecnologia provoca grande impacto no imaginário de uma coletividade, pois realinha os limites entre o possível e o impossível para o ser humano. Novos meios de investigação dos fenômenos naturais desnudam o que até então era considerado sobrenatural, atribuindo ao ser humano poderes até este momento reservados aos deuses. Em reação a esses avanços, os escritores do fantástico incorporam a linguagem objetiva da ciência e do jornalismo para descrever eventos inicialmente indevassáveis para a lógica e a razão. Além disso, desenvolvem uma série de motivos e temas que superam - por renovação ou inovação - aqueles sobrenaturais saídos da cultura popular ou da religião, criando um sobrenatural "laico". Este é preferido pela crítica por ser expressão de uma estética desvinculada de uma cultura específica, porém é mais uma referência do que uma regra, por estar fora do entendimento do público em geral.

O conflito entre percepção e consciência e seu proveito na narrativa fantástica foi inicialmente apontado por Freud (2010) em seu célebre artigo "O inquietante" (“Das Unheimlich", 1919) sobre o conto "O homem da areia", de E. T. A. Hoffmann (1817). Embora Freud tenha se preocupado mais em lidar com a questão do complexo de castração, indubitavelmente seu conceito de inquietação dentro da narrativa fantástica acaba por lidar também com a questão do duplo e das coincidências fortuitas, bem como dos estados alterados de consciência, ainda que em menor grau. 
Um indício de que essas últimas duas forças estariam em andamento tanto numa narrativa de ficção quanto na vida real seria o sentimento de que algo familiar apresenta traços de estranheza, tanto quanto algo estranho poder ser reconhecido como vagamente familiar. O que nos importa nessa reflexão é o fato de que a leitura desses eventos não se construiria na medida em que é realizada, mas que já se encontra previamente engatilhada em nossa mente, esperando apenas o sinal correto para disparar.

Dessa forma, a arte se torna um meio privilegiado de lidar com essas questões, tornando possível um discurso que a ciência - em função de suas limitações metodológicas - não pode assumir. Existem processos na natureza percebidos pelos sentidos humanos, mas que são previamente processados pelo cérebro, antes mesmo que tomemos conhecimento do que os causa. A prática da ciência exige o "desligamento" desse sistema para evitar chegar a falsas conclusões baseadas em erros de percepção e de consciência (DUNBAR, 2010). Para a arte, no entanto, trata-se de uma dimensão simultânea àquela em que vivemos, a qual a objetividade do método científico não pode desvendar e que a arte não representa, mas recria dentro de suas também limitações de linguagem. Enquanto a ciência nos apresenta a realidade como ela deve ser, a arte o faz como ela pode ser. Nossa competência de detecção da verossimilhança se baseia naquilo que é humanamente previsível e não aquilo que seja cientificamente plausível. Por isso, entre uma explicação científica e uma artística, é esta última que melhor atenderá a essa competência e à qual os seres humanos prestarão mais atenção e darão mais crédito. 


\section{ORIGENS: CRIAÇÃO COM DOCUMENTO DE FUNDAÇÃO OU PERDIDA NA ORIGEM DOS TEMPOS?}

Das mais diversas questões envolvendo a narrativa fantástica, uma das mais incômodas é a da sua origem. Afinal, ela de fato surge no contexto do Romantismo com os contos de E.T.A. Hoffmann (início do século $\mathrm{XIX}$ ), no romance gótico inglês ( $O$ castelo de Otranto, 1764) ou, como defendia Jorge Luis Borges, sempre existiu e é inútil tentar fazer distinções e classificações?

Primeiramente precisamos entender que textos não são seres vivos, embora se use à exaustão metáforas do gênero para lidar com as artes e a cultura em geral. Um texto não nasce de outro texto, mas da mente de um autor que muitas vezes não teve contato com a narrativa pretendida como ancestral daquela que este produz. Um caso muito comum é o de escritores considerados "kafkianos" que, ao serem questionados, alegam nunca terem lido as obras de Kafka. Tampouco podemos alegar um atavismo pan-humanístico que permite acessar uma "memória genética" comum a todos os seres humanos, onde as narrativas mais primitivas da humanidade estejam armazenadas no cérebro de cada descendente de cada testemunha de algum evento fundamental localizado em um passado remoto.

É mais próximo do verificável se entendermos que a experiência humana é limitada a um conjunto finito de situações que se repetem indefinidamente e que nossa capacidade de depreensão dos fenômenos que testemunhamos ou cujo testemunho aprendemos é igualmente limitada. Essa experiência, contudo, é aproximadamente a mesma desde que começamos a produzir arte e a contar histórias. 
As mudanças na arte em geral e na literatura em específico ocorrem na medida em que a experiência humana sofre alterações drásticas em seu andamento: eventos até então inauditos dependem de novos meios de compreensão e expressão, mas até que determinadas técnicas narrativas se consolidem, o evento desencadeador pode se perder sob as areias do tempo. Também é possível que a conscientização acerca do evento demore a ocorrer, dependendo das condições socioculturais das populações envolvidas e resulte numa produção que tardiamente se manifeste a respeito dele. É igualmente possível que algum autor ou grupos de autores depreendam tais eventos antes de eles se tornarem perceptiveis ao restante de sua coletividade e seu trabalho também se perca para ser redescoberto anos, décadas ou mesmo séculos depois de sua publicação original.

Por essas razões, concordamos com Bozzetto (1992) e Bozzetto e Huftier (2004) segundo os quais a Revolução Industrial do século XIX criou uma fratura no modo de vida de populações que mantinham relações datadas do neolítico (10.000 a 3.000 a. C.). Considerando que essas relações se baseavam em justificações e explicações próximas da experiência sensorial imediata em função das condições ecológicas circunvizinhas, essa fratura substituiu, sem chance de assimilação, o antigo sistema vigente, varrendo em seu esteio, todo o conjunto de crenças que até então o sustentava e era sustentado por ele - além de profundas e gravíssimas desigualdades e injustiças sociais.

Segundo Fabre (1992), isso resulta no conflito entre dois eixos, que ele chama, respectivamente, de tempo vertical e tempo horizontal, sendo o primeiro o da mentalidade mágica e 
o segundo o da científica. A mentalidade mágica é aquela que a tudo explica e torna o mundo um lugar seguro e reconfortante, pois tudo nele tem sua hora e lugar; já a científica é uma fonte intelectual de inquietação, pois depende, além da racionalidade e da lógica, de recursos tecnológicos muitas vezes indisponíveis ou inconcebíveis para formular suas hipóteses ou chegar a respostas seguras e reconfortantes. O homem da verticalidade vive no mundo da horizontalidade (porque foi obrigado a isso pela Revolução Industrial) e sabe como viver nela, mas mesmo diante das dificuldades impostas por esta, recorre à mentalidade mágica para solucionar seus conflitos internos. O mesmo não pode ser feito pelo homem da horizontalidade, pois seus vínculos com a mentalidade mágica foram cortados e ele não se sente no direito de recorrer a ela em caso de crise. Tal fenômeno é chamado por Fabre de "esquizofrenia prometeica", uma referência ao mito de Prometeu, deus que roubou o fogo do Olimpo para dá-lo aos homens e foi condenado ao castigo eterno de ter seu fígado devorado por um corvo.

A ideia que emprestamos de Fabre (1992) é de que o artista, diante da impossibilidade de voltar a uma narrativa que explore o além no qual residia a justiça sobre os homens, busca contar histórias em que eventos incompatíveis com a horizontalidade não remetam diretamente à verticalidade. Trata-se de uma espécie de laicização dos temas e motivos presentes tanto nos mitos e lendas quanto nos contos maravilhosos e de fadas, mas não exatamente uma continuidade ou evolução desses gêneros narrativos. A continuidade reside somente na limitação do ser humano de depreender sua realidade em termos de narração 
e não no aperfeiçoamento das técnicas narrativas. Estas são atualizadas de forma a acompanhar o progresso científico e tecnológico que reestrutura a noção de real pelo realinhamento dos limites entre possível e impossível e reconfiguram, por sua vez, nossa competência de verossimilhança.

Dessa forma, podemos entender que mesmo o sobrenatural tendo sido empregado em narrativas de ficção (e de não ficção) desde o início dos tempos, ele não se contrapunha ao real, ao contrário, fazia parte dele. A narrativa fantástica só se torna possível quando nossa competência de verossimilhança entra em uma espécie de "curto-circuito": embora a cultura civilizada nos ensine que o sobrenatural de fato não existe ou não pode ser comprovado, intuitivamente somos impelidos a discordar, mas, formalmente, impedidos de assumi-lo, pois numa sociedade calcada nos valores do capitalismo o sobrenatural é passível de desconfiança, senão de desprezo, pelos seus membros respeitáveis, visto que, numa civilização como a ocidental se tornou após a revolução industrial, apenas a narrativa realista ou o discurso científico são merecedores de crédito e seus autores reconhecidos como pessoas sérias e consideradas membros respeitáveis da sociedade: o cidadão de bem é aquele que desconfia de tudo e de todos, sempre. Toda condescendência para com a fantasia ou a ilusão é tida como irresponsável e os contos maravilhosos e de fadas são destinados somente às crianças e aos ignorantes ainda suscetíveis a descrições e narrações inverificáveis.

E é somente a partir do Romantismo do século XIX que essas condições socioculturais se apresentam de maneira a inspirar seus autores a adotar o realismo narrativo e o cientificismo 
discursivo para lidar com fenômenos sobrenaturais, colocando em cena o cidadão sempre desconfiado de tudo e de todos como testemunha privilegiada. Seus protagonistas não raro são jovens, ricos (ou nem tanto, mas raramente são pobres), solteiros e letrados repentinamente acometidos de coincidências fortuitas ou de estados alterados de consciência - ao menos é o que eles próprios usam como argumento em favor de sua sanidade mental. Mergulhados na incerteza e na insegurança, buscam freneticamente por provas de que tudo não passa de uma ilusão ou de que estejam gravemente doentes.

Nesse contexto sociocultural, tais narrativas não são simplesmente argumentos disfarçados de histórias para facilitar seu entendimento ou disseminar uma ideologia. Qualquer texto ou discurso já está previamente julgado pela visão de mundo do leitor ou interlocutor antes mesmo de ser escrito. Argumentos baseados em princípios desmistificados pela Ciência podem ser desacreditados pelo público quando este compreende e domina a metodologia empregada para tanto. A narrativa fantástica, porém, lida com a reação primitiva do ser humano diante do desconhecido, a de atribuir a qualquer fenômeno misterioso a ação de um agente dotado de vontade e interesses próprios, possuidor de informações privilegiadas a respeito de determinados assuntos (BOYER, 2001). Essa reação, involuntária e instintiva, é recuperada quando nos encontramos diante de um fenômeno inexplicável: enquanto o homem da horizontalidade vê nesse sobrenatural "laico" uma fonte de inquietação que abala sua razão, provocando uma experiência imaginária dos limites da razão (BESSIÈRE, 1974), para o homem da verticalidade, a maioria do contingente leitor, trata-se de 
uma confirmação de suas crenças, a prova da ação de entidades sobrenaturais que escolheram formas sutis de se comunicar com alguns poucos escolhidos.

De certa forma as criaturas sobrenaturais, que originalmente eram a personalização de um fenômeno natural desconhecido (e por isso mesmo o tornavam compreensível), acabam por se tornar reais não como forma de defender sua própria existência, mas a do modo de vida de seus autores e leitores, enfim, a relação com o mundo que representavam. No Romantismo, os autores buscavam a unidade perdida entre o humano e o meio ambiente que ele habitava em tempos antigos, como o era no tempo das narrativas populares da Idade Média, uma época em que, segundo os ideais românticos, cada coisa tinha sua hora e lugar e nada era determinado pela vontade do homem, mas dos deuses.

Responsabilizar-se pelo próprio destino, como propagado pelo então novo mito do self-made man, que luta sozinho contra as forças de um mundo sem deuses, é, além de uma fonte de inquietação, também de angústia, pois retira das pessoas o direito de se resignarem com sua sorte, obrigando-as a estar sempre em movimento, sempre em busca de algo que muitas vezes nem se sabe o que é. Ter, por exemplo, a consciência de que o éter é desabitado e que a qualquer momento é possível ser acometido por uma desgraça de origem e destino aleatórios é simplesmente desesperador. O ser humano depende de um propósito para a sua vida nem que seja a promessa de que somente depois da morte suas perguntas serão respondidas. Por essas razões é que a narrativa fantástica, como a conhecemos hoje, só poderia ter se originado no contexto do Romantismo europeu do século XIX. 


\section{O PROGRESSO TECNOLÓGICO E O IMPACTO NA VISÃO DE MUNDO DO LEITOR}

O segundo fator que, segundo nossa abordagem, influencia na produção e recepção da narrativa fantástica é a relação que a mente humana mantém com o mundo real. Alguns estudos (DENETT, 2006; HOOD, 2012) chegam a propor que a consciência é uma ilusão construída pelos nossos sentidos, embora - e com isso concordamos - não neguem a realidade referencial como independente dela.

Independentemente do nível tecnológico em que nos encontremos, nossa consciência se apropria dos dados captados pelos nossos órgãos do sentido de forma enviesada. O viés de confirmação (HINES, 2003; DUNBAR, 2010) é uma forma de interpretar as informações disponíveis em nosso meio ambiente antes mesmo que nos conscientizemos a respeito delas. Em tempos primitivos, cerca de 150 mil anos atrás, num período chamado de pleistoceno, aqueles que percebessem um predador disfarçado ou escondido no meio ambiente tinham mais chances de sobreviver e de passar adiante seus genes. Mais do que isso, aqueles que percebessem um predador mesmo onde ele não estivesse tinham mais chances ainda de continuarem vivos e perpetuarem essa característica em seus descendentes.

Entretanto, o que era uma vantagem evolutiva durante milênios tornou-se um problema em tempos modernos. Segundo Boyer (2001), o meio ambiente do ser humano é a informação. Sentimonos mais seguros e confortáveis num lugar do qual possamos extrair o máximo de dados e usá-los a nosso favor. Quando o ambiente 
não nos oferece informações em quantidade ou qualidade suficiente, entra em ação o viés de confirmação, o qual preenche os "vazios informacionais" com dados preconcebidos ou mesmo inventados. Não se trata evidentemente de um pacote de crenças previamente instalado em nossa memória antes de nascermos, mas sim a tendência hereditária de acreditar que todo evento de causa desconhecida é produzido por um agente intencional portador de informação privilegiada - como um predador mimetizado com seu ambiente, que pode nos ver, mas está invisível a nós.

O viés de confirmação não pode ser desabilitado, mas pode ser temporariamente saciado e, no decorrer de uma educação científica e uma vivência em ambiente seguro, eliminar o maior número possível de ocasiões que o desencadeiem. A revolução industrial e o lluminismo permitiram, ao menos às camadas mais privilegiadas da sociedade, um grau de instrução consistente o suficiente para saciar grande parte dos temores ancestrais materializados e, por que não, naturalizados pelo folclore e demais narrativas de ficção. Foi como se o paradigma explanatório reinante até então fosse repentinamente substituído por outro que não tinha passado pelo crivo do imaginário popular. As histórias que sobreviveram até nossos dias são lembradas e recontadas não porque são verdadeiras ou bem elaboradas, mas porque melhor atendem às nossas expectativas de atribuir agência a eventos de causa desconhecida.

Entretanto, não basta apenas apresentar explicações científicas para convencer as pessoas de que certos eventos de causa anteriormente desconhecida são naturais. É preciso apresentar provas verificáveis desses eventos, acessíveis mesmo àqueles 
desprovidos de uma educação formal. A nosso ver, foi o domínio da eletricidade que deslocou os limites entre o possível e o impossível, deixando uma margem menor de matéria-prima para os escritores trabalharem suas narrativas. Mesmo quando Mary Shelley escreve Frankenstein, ou o moderno Prometeu (1818), mais do que mistificando um experimento científico e oxigenando a narrativa fantástica e a ficção científica, ela escreve um atestado de que o homem podia não ter tomado o lugar dos deuses, mas se apossou definitivamente de alguns de seus segredos.

A eletricidade tornou a noite clara como o dia, permitiu a fabricação de máquinas e equipamentos que maximizam o poder do ser humano de modificar o meio em que vive. Num mundo transformado pela tecnologia, muito do que era um ato caprichoso de alguma criatura sobrenatural passou a ser uma ordem dada por um cientista a uma máquina. Por outro lado, os avanços da medicina, principalmente na cirurgia e na produção de drogas, proporcionaram curas ou paliativos que substituíram paulatinamente o recurso a meios mágicos. Entretanto, não podemos nos esquecer de que esses progressos só foram possíveis graças ao princípio do Capitalismo segundo o qual investem-se grandes somas em pesquisa visando seu retorno em lucro, como é o caso das patentes e dos produtos de consumo.

O que parece ser, portanto, uma revolta dos artistas contra as injustiças sociais provocadas pelo Capitalismo e contra a destruição de um modo de vida em que haveria menos violência e injustiças, pode ser na verdade a luta pela preservação de um discurso independente das amarras do real ou do ônus comprobatório de qualquer afirmação ou proposta. Porém, os autores precisam 
enfrentar o interesse crescente do público leitor por informações que tornem sua vida mais segura e confortável na disputa pela sobrevivência numa sociedade extremamente competitiva. A lenda, o mito, o conto popular são desconsideráveis para esse público: no mundo pós-revolução industrial tudo deve ser útil, gerar lucro, ou é descartado.

Por essa razão foi necessário que os autores encontrassem outra forma de argumentar em favor do modo de vida ancestral, defendendo o sistema de crenças que o sustentava e, por sua vez, era sustentado por ele. A forma encontrada foi o fantástico, uma narrativa de ficção que explora uma "falha" em nosso sistema de depreensão do real, permitindo que, apesar das evidências científicas em contrário, prefiramos uma explicação sobrenatural para eventos de causa desconhecida.

\section{O CONFLITO ENTRE PERCEPÇÃO E CONSCIÊNCIA DIANTE DO DESCONHECIDO}

Estudos a respeito da dificuldade de penetrabilidade do discurso científico junto ao público em geral são bastante convergentes (HUMPHREY, 1999; HINES, 2001; DENETT, 2006; SAGAN, 2006; DAWKINS, 2009; DUNBAR, 2010). Basicamente esses trabalhos mostram que a maioria da população, embora conhecedora do progresso técnico e científico e desfrute de suas vantagens, acredita nas premissas que sustentam fenômenos que contrariam grandes descobertas científicas, mesmo quando essas premissas são flagrantemente pseudocientíficas. Segundo Dennett (2006), para um grande número de pessoas, a ciência é útil apenas quando confirma crenças (como a oração intercessora), 
nunca quando as debela. A que se deveria esse comportamento aparentemente irracional?

Se considerarmos os estudos na área da antropologia cognitiva e da psicologia evolutiva, tal postura faz todo sentido. Com base nos trabalhos de Hood (2012) e Shermer (2011) sobre nossas crenças e superstições, os de Humphrey (1999) e Hines (2001) sobre a pseudociência e o paranormal, e os de Boyer (2001), Atran (2004) e Dennett (2006) sobre os aspectos cognitivos da religião, podemos entender que o ser humano tem uma tendência natural e inevitável de atribuir agência a qualquer evento de causa desconhecida. Agência, nesse aspecto, significa basicamente que tudo o que acontece é obra de alguém que intencionalmente agiu tendo em mente algum objetivo que normalmente desconhecemos, mas que de alguma forma nos afeta.

Os seres humanos, contudo, não são simplesmente crédulos empedernidos que negam qualquer evidência contrária às suas crenças porque assim foram esculpidos pelas forças da Evolução. A considerar o trabalho de Wilson (2013), segundo o qual a humanidade trilharia o caminho da eussocialidade, viemos passando por um processo de seleção natural de grupo multinível. Isso significa que nossas coletividades, em função de contingências tanto ecológicas quanto sociais, organizaramse de maneira a otimizar comportamentos mais afeitos ao seu funcionamento, preservação e expansão. A forma mais bem sucedida encontrada para manter um grupamento humano coeso no direcionamento de seus esforços para um bem comum foi a elaboração e aperfeiçoamento constante de narrativas que dessem uma razão para estarmos neste mundo e que faríamos 
parte de uma coletividade com a qual devemos contribuir e buscar reconhecimento por essa contribuição.

Mas nada disso funcionaria sem outro mecanismo desenvolvido pelas pressões da seleção natural de grupo multinível: o sentimento de ser vigiado por olhos invisíveis e o medo de ser pego e punido pelo grupo em caso de descumprimento de sua parte na construção e manutenção da coletividade.

Entretanto, somente o medo de ser pego em flagrante delito de trapaça social não se sustenta com narrativas que atribuam a origem desse sentimento à ação de agentes sobrenaturais. É preciso que a experiência sobrenatural ocorra de fato e seja semelhante a todos os membros de uma coletividade para que a sensação de ser observado, juntamente com o medo de ser punido e com as narrativas que as explicam formem um conjunto indutor de uma cultura que mantenha e expanda essa sociedade. Essas experiências sobrenaturais do mundo real são os estados alterados de consciência (sonhos e substâncias entorpecentes) e as coincidências fortuitas (incompatibilidade entre expectativa e fato). Passar por tais situações ativa as emoções e sensações que evocam a ação de seres sobrenaturais e ativa o imaginário para explicações e justificativas que melhor deem coerência ao conjunto: são nossas narrativas hoje reconhecidas como não miméticas. No princípio, tais narrativas eram verossímeis e, por isso mesmo, realistas, pois estavam adequadas ao nível tecnológico da sociedade em que foram criadas.

É neste ponto que o artigo de Freud (2010) sobre o sentimento do inquietante (Unheimlich), publicado originalmente em 1919, é fundamental. Segundo o pai da psicanálise, o inquietante é um 
sentimento que surge do conflito entre percepção e consciência, salientado pelo fato de um evento ou objeto ser reconhecido como familiar mesmo sendo fatualmente estranho e vice-versa. Considerando as limitações da experiência humana - um número muito pequeno de coisas pode ocorrer a uma pessoa no decorrer de sua vida - ou dos relatos que se podem acompanhar sobre eventos não testemunhados, visto que um mesmo conteúdo se repete sob formas variadas, que por sua vez também são limitadas. Às vezes nos deparamos com situações aparentemente estranhas, mas que evocam certa familiaridade ou situações familiares que por uma razão ou outra nos desconcertam.

A ciência e a tecnologia criam situações novas para a mente humana, para as quais ela ainda não está preparada, e o mundo seguro e confortável, por ser previsível dentro das expectativas socioculturais dos indivíduos, desaparece. A narrativa fantástica é a prova de que ainda temos uma mente primitiva executando tarefas extremamente exigentes do ponto de vista tecnológico e civilizado para suas condições naturais. Mais do que isso, o progresso científico é muito rápido para ser acompanhado pelo imaginário do público em geral e os cientistas são, de certa forma, pessoas que estão passando progressiva e lentamente por um processo de seleção de grupo multinível na medida em que são necessários para expandir os lucros do Capitalismo e imediatamente recrutados quando percebidos como interessantes para essa finalidade. Não à toa há ramos da ficção científica que criticam o excesso de racionalidade na condução da sociedade, entregue a cientistas inescrupulosos ou impelidos somente pelo desejo de executar seus experimentos pelo simples fato de que são possíveis. 
É, por fim, a perda dos vínculos com um passado que fornecia as instruções sobre como lidar com o presente e se preparar para o futuro que permite o surgimento da narrativa fantástica. Ao reagir contra a destruição de seu modo de vida, os escritores do Romantismo defenderam um sistema de crenças por meio de técnicas narrativas que suscitam, mesmo nas mentes mais bem-educadas nos princípios científicos, a existência de um além sobrenatural que interfere em nossas vidas.

\section{A ARTE COMO MEIO PRIVILEGIADO DE EXPRESSAR A REALIDADE}

Uma das principais características da ficção, apontada por professores de literatura, é a flexibilidade no trato com a realidade referencial. Entretanto, não é raro textos teóricos e críticos da narrativa fantástica levarem em consideração questões como a da verossimilhança (RODRIGUES, 1986) e até mesmo da mimesis. Isso ocorre porque todos nós que estudamos o fantástico sabemos que, embora tenhamos uma mente ideologicamente alinhada com a causa científica - segundo a qual seres sobrenaturais não existem sabemos que uma narrativa de ficção não é inteligível se não puder ser reconhecida como plausível.

Conforme vimos discorrendo desde o início deste artigo, trata-se de uma condição incontornável de nossa natureza mental atribuir agência a qualquer evento de causa desconhecida e que nossa mente possui critérios para reconhecer uma explicação como aceitável para qualquer evento percebido como resultado de uma agência. As histórias que melhor combinam com esses critérios são aquelas que personificam as forças da natureza originalmente desconhecidas, pois, segundo Lakoff e Johnson (1986), ao trazermos 
fenômenos abstratos para o nível do humano, eles se tornam mais limitáveis e, por isso mesmo, mais compreensíveis.

A narrativa de ficção não é, portanto, simples recreação. As figuras de linguagem que a compõem são estruturas elementares de comunicação da mente com o mundo exterior, mas em função da progressiva complexidade da vida em sociedade, que passou a requerer discursos mais claros e precisos para melhor estabelecer as regras de funcionamento dessa mesma sociedade, as narrativas de ficção perderam seu status de componentes de um discurso portador da verdade. Numa sociedade mais simples, que mantém relações mais pragmáticas com o meio de que tiram sua subsistência, narrativas mais elementares bastam para apaziguar os anseios diante do desconhecido e tornar a realidade compreensível ou ao menos insuportável.

Existe, porém, um descompasso entre as necessidades discursivas de uma sociedade tecnologicamente avançada e a mente do ser humano. Ao longo de milênios sobrevivemos por entendermos o mundo em termos de causa e efeito e que a causa era sobrenatural. Num período de menos de um século (passagem do século XVIII para o XIX) nossas expectativas intuitivas deixaram de ser atendidas por narrativas que melhor se adequavam às suas inquietações e passaram a ser contrariadas por notícias de jornal e artigos científicos. A própria narrativa de ficção se modificou, incorporando elementos de ambos os gêneros e criando um abismo entre as narrativas que lidam com as necessidades do imaginário e as que problematizam de forma racional os fatos da vida contemporânea. 
Contudo, retomando Fabre (1992), o homem da verticalidade está presente na mente do homem da horizontalidade, mas o contrário não é verdadeiro. Na medida em que a narrativa fantástica reconforta - embora assuste - o ser humano tributário do pensamento mágico, é ao cientificista que ela inquieta. Não somente enquanto estrutura narrativa aparente que denuncia seu próprio processo de composição e ficcionalidade, mas também enquanto reveladora de uma realidade que pouco mais de dois séculos de racionalidade não puderam eliminar.

Dessa forma, podemos afirmar que o discurso científico pode não se infiltrar na mente de todas as pessoas, mas o ficcional é universal justamente porque evoluímos para aceitá-lo como estrutura de explicação para aquilo que não podemos ver e cujos resultados das ações são patentes. E é exatamente por isso que a narrativa fantástica desconcerta críticos e teóricos que tentam entendê-la por meio de critérios oriundos das ciências naturais (VAX, 2002): ela não pode ser entendida por si mesma, somente a partir da letra fria do texto; depende da compreensão do sistema sociocultural no qual surgiu e dos mecanismos cognitivos que a tornam inteligível.

Assim, é necessário entendermos a verossimilhança como uma competência de leitura que busca em todo discurso ficcional ou não - sua plausibilidade. A ação de seres sobrenaturais é perfeitamente plausível para uma mente que foi selecionada pelas pressões de grupo multinível (WILSON, 2013) para entender fenômenos abstratos por meio do mecanismo de linguagem da personalização. Por isso o fantástico é uma expressão artística por meio da qual o escritor desperta em seu leitor o senso do 
sobrenatural por meio de situações que, de forma verossímil, atacam a visão racionalista do mundo.

A vida em sociedade selecionou aqueles que mais adequadamente se adaptaram a ela e cooptou seus mecanismos de interação com o mundo para fazer dela um universo à parte, no qual as leis da linguagem estão acima da experiência sensível. É por isso que a arte e, mais especificamente a literatura, nos proporcionam uma experiência significativa que, ao desafiar ou reiterar nossas crenças, interferem em nosso processo de tomada de decisões, afetando a maneira como agimos e permitimos que ajam sobre nós em nossas coletividades - assunto que precisa ser debatido em ocasiões futuras.

\section{CONCLUSÃO}

A narrativa fantástica não é um experimento de linguagem praticado por um autor que explora os limites estéticos da verossimilhança com o objetivo de impressionar o intelecto de um leitor cético. Embora tudo possa de fato acontecer numa narrativa de ficção, sua inteligibilidade depende da competência que os seres humanos naturalmente desenvolvem para avaliar a plausibilidade de um evento narrado, que é a verossimilhança. Conforme o nível tecnológico de uma sociedade evolui, a plausibilidade de um evento ocorrer pode aumentar ou diminuir, mudando a noção de real de sua população. Entretanto, mesmo uma mente cientificamente capacitada é suscetível a sensações e emoções geradas a partir de experiências que remetem ao medo ancestral do desconhecido. Pesquisas recentes em antropologia cognitiva e psicologia evolutiva demonstram que evoluímos para evitar predadores mimetizados 
com o ambiente em que vivíamos cerca de 150 mil anos atrás. Com o tempo, nossas relações com esses predadores evoluíram a ponto de nós mesmos nos tornarmos os maiores predadores do planeta, mas em função do caminho que tomamos para viver em grandes grupos, esse medo ancestral foi cooptado para manter a coesão social através de narrativas que inicialmente explicavam as razões pelas quais a coletividade deveria ser mantida e expandida, tais como o mito e a lenda. Na medida em que a tecnologia avançava, tais narrativas se sofisticavam para equilibrar a nova concepção de mundo que se tornava acessível ao público em geral com a manutenção da união de grupo. A revolução industrial do século XIX, todavia, acelerou esse processo de avanço tecnológico num intervalo muito curto e destruiu relações sociais que permeavam o imaginário popular há milênios, deixando o serhumano desamparado em relação ao seu futuro e ao seu passado. Ao tentarem recuperar tradições narrativas da Idade Média em socorro de um mundo que se desfazia diante de seus olhos, os escritores do Romantismo conseguiram aliar ao discurso científico e jornalístico aos temas e motivos mais recorrentes da literatura ocidental e deram origem ao fantástico: uma narrativa que conseguia despertar mesmo nas mentes mais céticas o sentimento de que um além sobrenatural era possível, ainda que inominável e invisível.

A partir dessas considerações, concluímos que novas ferramentas de análise e interpretação da narrativa fantástica, originadas na antropologia cognitiva, na psicologia evolutiva e do desenvolvimento devem ser incorporadas às já dominadas pelos estudos literários para entendermos não apenas o que é e como se manifesta uma narrativa de ficção, mas também por 
que elas podem nos afetar emocionalmente a ponto de interferir em nosso processo de tomada de decisões que envolvem a vida em sociedade e nossa relação com a realidade referencial. Vários estudos já abordam as relações entre literatura e cognição, mas o caso do fantástico, bastante estudado pela psicanálise e pela sociologia e, diante dos becos sem saída a que tais trabalhos chegaram (demonstrados pelos remendos teóricos apresentados), exige uma combinação mais sólida entre todas essas ciências, corroborando a adoção de uma abordagem sociocognitiva. Assim poderemos entender como nossa mente aceita como sendo verossímeis eventos que não se sustentam diante da mais elementar prova de realidade, mas que se constituem numa experiência significativa para nosso imaginário.

\section{REFERÊNCIAS}

ATRAN, Scott (2004). In gods we trust: The evolutionary landscape of religion. New York: Oxford University Press.

BESSIÈRE, Irène (1974). Le récit fantastique. La poétique de I'incertain. Paris: Larousse.

BOYD, Brian (2009). On the origin of stories. Evolution, cognition and fiction. Cambridge/London: The Belknap of Harvard University Press.

BOYER, Pascal (2001). Et l'homme créa les dieux. Comment expliquer la religion. Paris: Gallimard.

BOZZETTO, Roger (1992). L'obscur objet d'un désir. Fantastique et science-fiction: deux littératures de l'imaginaire. Aix-en-Provence: Presses Universitaires de Provence.

BOZZETTO, Roger; HUFTIER, Arnaud (2004). Les frontières du fantastique. Approches de l'impensable en littérature. Valenciennes: Presses Universitaires de Valenciennes.

CESERANI, Remo (2006). O fantástico. Londrina: Eduel. 
DAWKINS, Richard (2009). O maior espetáculo da Terra. As evidências da evolução. São Paulo: Companhia das Letras.

DENNETT, Daniel (2006). Quebrando o encanto. A religião como fenômeno natural. Rio de Janeiro: Globo.

DUNBAR, Robin (2010). The trouble with science. London: Farber and Farber.

FABRE, Jean (1992). Le mirroir de sorcière. Essai sur la littérature fantastique. Paris: José Corti.

FREUD, Sigmund (2010). “O inquietante”. In: Obras Completas (1917-1920). Vol. 14. São Paulo: Companhia das Letras. p.328-376.

GRIVEL, Charles (1997). Fantastique-fiction. Paris: Presses Universitaires de France.

HINES, Terence (2003). Pseudoscience and the paranormal. New York: Prometheus Books.

HOOD, Bruce (2012). Supersentido. Por que acreditamos no inacreditável. Ribeirão Preto: Novo Conceito.

HUMPHREY, Nicholas (1999). Leaps of faith. Science, miracles and the search for supernatural consolation. New York: Copernicus.

LAKOFF, George; JOHNSON, Mark (1980). Metaphors we live by. Chicago and London: University of Chicago Press.

LOVECRAFT, Howard Philips (2008). O horror sobrenatural em literatura. São Paulo: Iluminuras.

MELLIER, Denis (1999). L'écriture de l'excès. Fiction fantastique et poétique de la terreur. Paris: Honoré Champion.

MOLINO, Jean (1980). "Le fantastique entre l'oral et l'écrit". In: Europe Revue Littéraire, 611, 32-40.

PRINCE, Nathalie (2008). Le fantastique. Paris: Armand Colin.

RODRIGUES, Selma Calazans (1986). O fantástico. São Paulo: Ática.

SAGAN, Carl (2006). O mundo assombrado pelos demônios. A ciência vista como uma vela no escuro. São Paulo: Companhia das Letras.

SHERMER, Michael (2011). Por que as pessoas acreditam em coisas estranhas. Pseudociência, superstição e outras confusões dos nossos tempos. São Paulo: JSN. 
TODOROV, Tzvetan (1969). Introduction à la littérature fantastique. Paris: Seuil. VAX, Louis (2002). Les philosophes au pays des spectres. Nancy: Presses Universitaires de Nancy.

WILSON, Edward Osbourne (2013). A conquista social da Terra. São Paulo: Companhia das Letras. 